J. Lake Sci. (湖泊科学), 2015, 27(3):392-400

http: //www. jlakes.org. E-mail : jlakes@niglas.ac.cn

(C) 2015 by Journal of Lake Sciences

\title{
海拔对纳帕海季节性湿地植被分布格局影响初探"
}

\author{
陈 剑 ${ }^{1,2,3}$, 缪福俊 ${ }^{1,2,3}$,杨文忠 ${ }^{1,2,3}$, 原晓龙 ${ }^{1,2,3}$, 王 娟 ${ }^{1,2,3}$, 周 妍 ${ }^{4}$,杨宇明 ${ }^{1,2,3 * *}$ \\ (1: 国家林业局云南珍稀濒特森林植物保护和繁育实验室,昆明 650201) \\ (2:云南省森林植物培育与开发利用重点实验室,昆明 650201) \\ ( 3 : 云南省林业科学院, 昆明 650201 ) \\ (4 : 国家林业局竹子研究开发中心,杭州 310012)
}

\begin{abstract}
摘 要: 利用物种海拔分布范围 $\left(R_{\mathrm{s}}\right)$ 作为定量研究物种对环境适应能力的一个基础指标, 以纳帕海季节性湿地这样一个 近似平面的生态系统做为研究对象, 结合 GIS 技术和野外实地调查, 对物种分布格局、物种对水因子的适应性、水因子分 布梯度和优势物种分布面积进行统计和可视化分析. 研究结果表明: 研究区域内优势物种的分布受水因子分布梯度的显 著影响,在物种处于同一主导因子作用的情况下,处于同一竞争水平物种的分布面积与 $R_{\mathrm{s}}$ 没有明显相关性,但与基于 $R_{\mathrm{s}}$ 的 $M_{\mathrm{sh}}$ 值 (物种海拔分布范围中间值与当地海拔的差值) 则表现出明显的负相关关系. 结论说明 $M_{\mathrm{sh}}$ 可作为定量研究物种 对环境适应能力的一个指示指标,该指示指标可能对解释生态系统内物种分布格局有重要的生态意义.
\end{abstract}

关键词: 物种海拔分布范围; 主导因子;分布面积; 纳帕海

\section{A preliminary study on impacts of the elevation on plants' distribution patterns in seasonal wetland of Lake Napahai}

CHEN Jian ${ }^{1,2,3}$, MIAO Fujun ${ }^{1,2,3}$, YANG Wenzhong ${ }^{1,2,3}$, YUAN Xiaolong ${ }^{1,2,3}$, WANG Juan ${ }^{1,2,3}$, ZHOU Yan ${ }^{4} \&$ YANG Yuming ${ }^{1,2,3}$

(1: Key Laboratory of Rare and Endangered Forest Plant of State Forestry Administration, Kunming 650201, P. R. China)

(2: Yunnan Provincial Key Laboratory of Cultivation and Exploitation of Forest Plants, Kunming 650201, P. R. China)

(3: Yunnan Academy of Forestry, Kunming 650201, P. R. China)

(4: China National Bamboo Research Centre, Hangzhou 310012, P. R. China)

Abstract: This study used plant species' distribution range along elevation $\left(R_{\mathrm{s}}\right)$ as the basic indicator to quantitatively study the plant's environmental adaptation capacity within Lake Napahai seasonal wetland ecosystem. Throughout field survey and GIS technology, this paper synthetically analyzed the plant distribution pattern, the species' adaption to water factor and gradient distribution of water, and the dominant plant species' distribution area. The results showed that the distribution of the dominant plant species was largely affected by the distribution gradient of water factor. Under the same leading ecological factor (water), the distribution area of the dominant species at the same competitive level had no significant correlation with the $R_{\mathrm{s}}$ while had apparent logarithmic negative correlations with the absolute difference value of altitudinal distribution range minus local elevation $\left(M_{\mathrm{sh}}\right)$, finding explained that $M_{\mathrm{sh}}$ could be an indicating parameter for quantitative research on plant species environmental adaptation capacity, which might have significant ecological meaning on illustrating plant species distribution pattern in such an ecosystem.

Keywords: Altitudinal distribution range; leading ecological factor; distribution area; Lake Napahai

种域 (Species Range) 即物种的分布范围, 不仅包括物种的平面分布范围, 也包括物种的海拔分布范围,

* 亚太森林网络(APFNet)一联合国大学项目 (UNU)、东南半岛跨境生态安全森林植被恢复项目 (600UU-1123)、 NSFC一云南联合基金重点项目 (U0933601) 和国家自然科学基金项目 (30600080,31060077) 联合资助. $2014-04-$ 09 收稿;2014-09-04 收修改稿. 陈剑( 1978 ), 男, 硕士, 研究实习员;E-mail : chenjianyaf@ 126. com.

** 通信作者;E-mail:yymbamb@163.com. 
它是物种的基本生物地理属性 ${ }^{[1]}$, 基于各种生态因子随地理空间的变化, 种域概念在生态学研究中有较广 泛的应用,如种域对 Rapoport 法则的检验 ${ }^{[2-3]}$ 、种域与气候变化的关系 ${ }^{[4-5]}$ 、种域对物种遗传变异的影响 ${ }^{[6]}$ 等 方面的研究. 因为生态因子随海拔变化更为明显, 在空间范围上也更便于开展研究, 故更多的研究主要集中 于植物生存发展所受各种随海拔梯度变化的生态因子的影响, 如植物生产力与生物量 ${ }^{[7-9]}$ 、生理性状 ${ }^{[10-11]}$ 、 生物多样性与群落变化格局 ${ }^{[12-13]}$ 等, 并且这些研究均把研究范围限制在一定区域内 (如省级或更小的地理 范围), 因为研究区域过大 (如全国乃至世界范围), 则会明显地引人因纬度变化而导致的生态因子变化,干 扰生态因子随海拔梯度变化这一研究前提.

物种在一定区域内的海拔分布范围可作为研究物种对该区 域内综合环境因素适应能力的一个指示指标, 即“海拔分布范围 越宽的物种,对综合环境因子有越大的适应能力”,有可能利用 该指标反过来对物种在不同海拔上的生存发展状态或不同物种 在同一海拔上的生存发展状态进行定量分析, 但目前这方面的研 究还鲜见报道.

基于此,可有以下研究假设 ( 3 个相关参数如图 1 所示) :

假设 1 : 海拔分布范围 $R_{\mathrm{s}}$ 越宽的物种, 对综合环境因子有更 大的适应能力, 在处于同一海拔生态系统中, 可能比 $R_{\mathrm{s}}$ 较窄的物 种具有更大的分布面积.

假设 2 :受中域效应设想 ${ }^{[14-15]}$ 的启发, 可假设物种在其海拔 分布范围的中间值 $R_{\mathrm{m}}$ 能获得其生态因子需求的最佳满足程度,

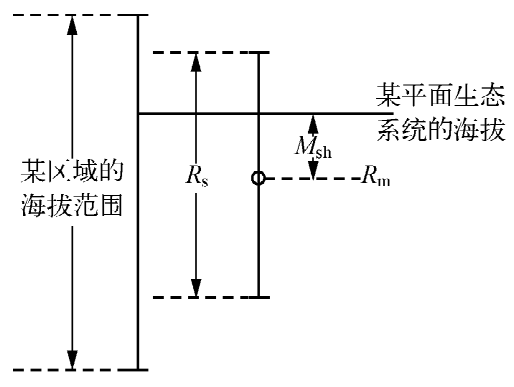

图 1 参量 $R_{\mathrm{s}} 、 R_{\mathrm{m}}$ 和 $M_{\mathrm{sh}}$ 的示意图

Fig. 1 Sketch for 3 parameters of $R_{\mathrm{s}}, R_{\mathrm{m}}$ and $M_{\mathrm{sh}}$ $M_{\mathrm{sh}}$ 为某物种所处现实生境的海拔 $E_{\mathrm{r}}$ 与 $R_{\mathrm{m}}$ 的差值, 则有某物种在 不同海拔梯度上, $M_{\mathrm{sh}}$ 值越小, 可能表现出越大的分布面积; 而同一海拔上, 某物种 $M_{\mathrm{sh}}$ 值越小, 则可能较其它 物种占有越大的分布面积.

以上假设的限制条件: (1) 对比研究物种应具有相同的主导因子, 如水生植物不能与旱生植物对比研究, 因 $R_{\mathrm{s}}$ 再宽的水生植物也不可能在干旱环境生长, $R_{\mathrm{s}}$ 再宽的旱生植物也不可能在水中生长. (2) 研究区域必须 为平面或近似平面的生态系统, 以保证物种分布在同一海拔上. (3) 对比研究物种在生态系统中应处于同一 竞争层次, 如均为草本.

所以物种的 $R_{\mathrm{s}} 、 R_{\mathrm{m}} 、 M_{\mathrm{sh}}$ 在某一海拔的现实平面生态系统中, 与物种的分布面积存在某种相关性,在此假 设基础上,本文拟利用某区域内植物物种海拔分布范围信息与该区域内某一平面生态系统中 (同一海拔) 的 植物物种分布格局进行研究, 以探索物种海拔分布范围这一指示指标在物种竞争、群落分布格局、群落演替 等方面的潜在用途.

\section{1 研究区域选择}

云南是一个地形海拔变化丰富的省份, 同时又存在各种面积的平原地形,适于对上述假设进行研究和 验证. 研究区域 $\left(27^{\circ} 49^{\prime} \sim 27^{\circ} 55^{\prime} \mathrm{N}, 99^{\circ} 37^{\prime} \sim 99^{\circ} 43^{\prime} \mathrm{E}\right)$ 为云南省迪庆州香格里拉县境内纳帕海自然保护区, 是大中甸盆地的一部分, 海拔 $3260 \mathrm{~m}$, 地形为三面环山的盆地, 地势平缓, 接近于一个平面, 研究区面积为 $2850.49 \mathrm{hm}^{2}$. 纳帕海为季节性湖泊, 通常 6-10 月为雨季, 以湖泊或沼泽景观为主; 11 月至次年 5 月以草甸 景观为主. 据相关资料显示, 纳帕海在 $1970 \mathrm{~s}$ 就已经完全排水疏干 (旱季 $)^{[16]}$, 其基质景观要素在年度内从水 体、沼泽、草甸等不同形式间大幅变化,在人工排水、放牧、围剭、旅游等多种强烈人工干扰条件下,纳帕海的 植物群落和物质能量流动态十分复杂, 历年来研究人员对纳帕海的研究主要集中在土壤分析 ${ }^{[17]}$ 、水生植被 调查 ${ }^{[18]}$ 、水土保持 ${ }^{[19]}$ 、退化评价指标体系 ${ }^{[20]}$ 等方面, 而对其植物群落分布格局内在机制的研究一直是个难 题, 至今未有较明确的结论.

纳帕海研究区域内植物物种全部为草本植物, 大多数物种均能适应水因子的剧烈变化, 水因子为该湿 地生态系统的主导因子, 这样的情况基本满足研究物种处在同一竞争层次的条件,且其平坦的地势更利于 调查物种的分布面积, 满足研究假设限制条件的要求, 同时大中甸盆地旱生生境下到处泛滥的大狼毒 
(Euphorbia jolkinii) 等旱生物种因为对水因子不耐受, 无法进人季节性湿地生态系统, 自然地隔绝了不符合 研究条件的物种.

\section{2 数据来源与研究方法}

\section{1 数据来源}

1) 湿地物种海拔分布范围数据来源于实地调查和云南省各类植物资源调查资料, 经过综合分析认为李 恒编著的《云南湿地植物名录》 ${ }^{[21]}$ 中的数据最为详实准确, 故数据以本书为主; 物种对水因子的适应性更多 地参考中国植物物种信息数据库 (http://db. kib. ac. cn) 中的信息, 因为该数据库较《云南湿地植物名录》更 详细地记录了物种生存的生境 (物种海拔分布范围数据没有参考中国植物物种信息数据库, 因其数据的范 围为全国乃至世界, 更大程度地引人了由于纬度变化而导致的生态因子变化, 这种情况不符合本研究中 “海 拔变化导致的综合生态因子变化”这一前提).

2) 物种、群落分布数据: 现有的遥感技术难以直接通过卫星影像准确判读草本群落, 所以本研究在借鉴 卫星影像分析的基础上(2002 年 12 月 10 日 Quickbird 影像、2011 年 1 月 6 日 ETM 影像),于 2011 年 6-7 月人工进行现地采集 GPS 点和勾绘群落图斑, 斑块以群落优势物种进行划分和命名.

\section{2 研究方法}

1) 研究参量定义

基于前言中的 3 个假设, 对相关参量作如下定义:

$$
R_{\mathrm{s}}=E_{\mathrm{h}}-E_{1}
$$

式中, $R_{\mathrm{s}}$ 表示物种海拔分布范围, $E_{\mathrm{h}}$ 表示该物种分布最高海拔, $E_{1}$ 表示该物种分布最低海拔.

$$
R_{\mathrm{m}}=\left(E_{1}+E_{\mathrm{h}}\right) / 2
$$

式中, $R_{\mathrm{m}}$ 表示物种海拔范围中间值.

$$
M_{\mathrm{sh}}=\left|\left(E_{1}+E_{\mathrm{h}}\right) / 2-E_{\mathrm{r}}\right|\left(M_{\mathrm{sh}} \geqslant 0\right)
$$

式中, $M_{\mathrm{sh}}$ 表示物种海拔分布范围的中间值与当地海拔的差, $E_{\mathrm{r}}$ 表示研究地当地实际海拔.

2) 数据处理

利用 ArcGIS 9.3 平台, 对纳帕海草本植物群落空间分布格局和面积进行统计分析; 根据水生植物群落 分布情况,对有效水因子分布梯度进行反演并进行可视化分析; 对各优势物种 $M_{\mathrm{sh}}$ 结合地理分布信息进行可 视化分析.

该过程分别用到 Spline(样条函数) 和 IDW (反距离权重) 插值.

Spline 插值 (Regularized) 计算方法 ${ }^{[22]}$ 为:

$$
\frac{1}{2 \pi}\left(\frac{d^{2}}{4}\left(\ln \left(\frac{d}{2 \tau}\right)+c-1\right)+\tau^{2}\left(k_{0}\left(\frac{d}{\tau}\right)+c+\ln \left(\frac{d}{2 \pi}\right)\right)\right)
$$

式中, $\tau$ 为样条中用到的权重, $d$ 为待定值点和控制点 $i$ 的距离, $c$ 为常数 $0.577215, k_{0}(d / \tau)$ 为修正的 0 次贝 塞尔常数,该函数适合空间连续变化且光滑表面的生成, 在本研究中用于对水因子分布梯度进行插值运算.

IDW 插值计算方法 ${ }^{[23]}$ 为:

$$
Z_{0}=\left[\sum_{i=1}^{n} \frac{z_{i}}{d_{i}^{k}}\right] /\left[\sum_{i=1}^{n} \frac{1}{d_{i}^{k}}\right]
$$

式中, $Z_{0}$ 为点 0 的估计值; $Z_{i}$ 为控制点; $d_{i}$ 为控制点到点 0 的距离; $n$ 为控制点数目; $k$ 为指定的幂, 插值点距 离控制点距离越远,所受其影响越低,在本研究中用于对 $R_{\mathrm{s}}$ 相关参数进行空间分布梯度插值.

3) 用 SPSS 19.0 对 $R_{\mathrm{s}} 、 M_{\mathrm{sh}}$ 与其对应的面积进行统计分析、相关性分析和制图. 


\section{3 结果与分析}

\section{1 纳帕海植物群落分布格局及主导因子特征}

实际研究区域面积为 $2850.49 \mathrm{hm}^{2}$, 植被类型全为草本, 区域内共有 26 类群落共计 191 个群落斑块, 群 落名称以群落内盖度最大的优势物种进行命名. 图 2 是纳帕海各种植物群落的平面地理分布格局, 值得强 调的是, 纳帕海植物群落在年度内随水因子的时空分布差异、物候差异等因素会有极大的变化,年度内的不 同时段或不同年度的相同时段,群落分布及构成物种都存在很大的差异, 本研究中的群落分布格局只是纳 帕海一系列动态变化中的一个阶段.

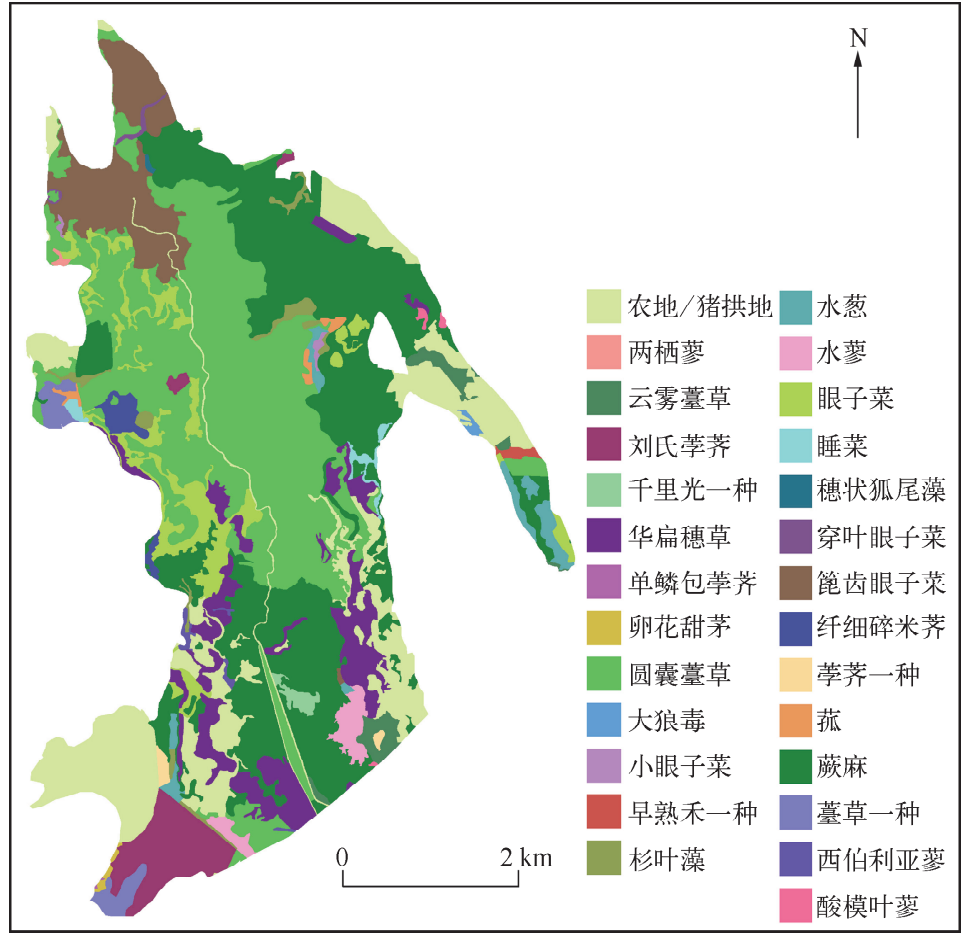

图 2 纳帕海植物群落分布

Fig. 2 Distribution of plant communities in Lake Napahai

群落在物种组成上最大的特点是, 基 本每一个群落斑块中, 都同时包括有适应 水生、湿生、中生的物种,并且很多物种并 不是单纯的水生或湿生植物,而是可以同 时适合多种水因子条件,根据物种对水因 子的适应能力, 本研究把纳帕海优势物种 分为水生、水生一湿生、水生一湿生一中生、 湿生一中生、中生一旱生 5 种适应类型, 如 水生一湿生一中生类型表示该物种在水 生、湿生、中生 3 种不同的生境中都能 生存.

各群落优势种按不同的水因子适应 能力统计出来的群落面积如图 3 所示, 在

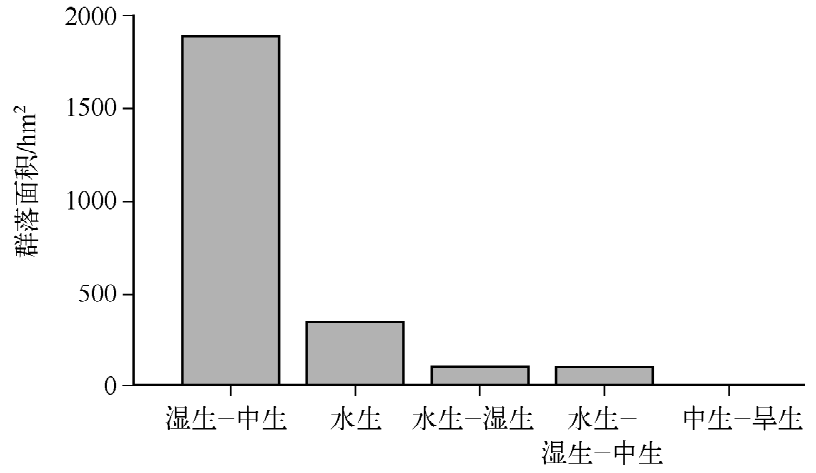

图 3 优势物种对水因子的不同适应性

Fig. 3 Different adaptabilities to water factor of dominant species 
调查时常见的 80 多个物种中, 大部分是适应湿生、中生的物种, 如水苶 (Polygonum hydropiper)、矮地榆 (Sanguisorba filiformis Hand)、两栖苶 (Polygonum amphibium)、偋麻 (Potentilla anserina), 湿生一中生型的物种所占 面积比例最大, 占总面积的 77\%, 水生一湿生型群落面积占总面积的 5\%, 水生型群落面积占总面积的 $14 \%$, 水生一湿生一中生型群落面积占总面积的 4\%, 中生一旱生型加上单纯中生、旱生的群落共计不到总面积的 $1 \%$, 只有极小的比例. 该结果表明纳帕海虽然在枯水期是草甸景观, 但从物种对水因子依赖性组成上可见, 它仍是一个以水因子为主导的生态系统, 总体上满足本研究假设的限制条件.

\section{2 纳帕海植物物种的 $R_{\mathrm{s}}$ 构成}

除去农地、猪拱地 (因附近村民散养的家猪破坏植被造成的裸地) 斑块, 所有群落斑块优势物种 $R_{\mathrm{s}} 、 R_{\mathrm{m}}$ 及其与 $E_{\mathrm{r}}$ 的距离见图 4, 各 $R_{\mathrm{s}}$ 变化范围为 $200 \sim 3650 \mathrm{~m}, R_{\mathrm{m}}$ 与 $E_{\mathrm{r}}$ 差值变化范围为 $60 \sim 3060 \mathrm{~m}$. 因沼生蔊菜 (Rorippa islandica)、早熟禾一种 (Poa sp.)、荣荠一种 (Heleocharis sp.) 3 个物种还未见明确的海拔上、下限分 布记录, 或是物种鉴定未能完成, 故 $R_{\mathrm{s}}$ 信息缺失, 在图中表示为下方 3 个 $y$ 轴值为 0 的点, 不参与数据分析.

各个斑块对应的 $R_{\mathrm{s}} 、 R_{\mathrm{m}}$ 、斑块面积如图 4 所示, 由于斑块破碎化程度较高, 各种 $R_{\mathrm{s}}$ 的物种连续分布都主 要集中在 $0 \sim 20 \mathrm{hm}^{2}$ 之间.

$R_{\mathrm{m}}$ 是各群落优势物种在海拔分布范围的中间值, 直观地显示了与纳帕海实际海拔 $E_{\mathrm{r}}(3260 \mathrm{~m})$ 之间的距 离 (即 $M_{\mathrm{sh}}$ 值) (图 4).
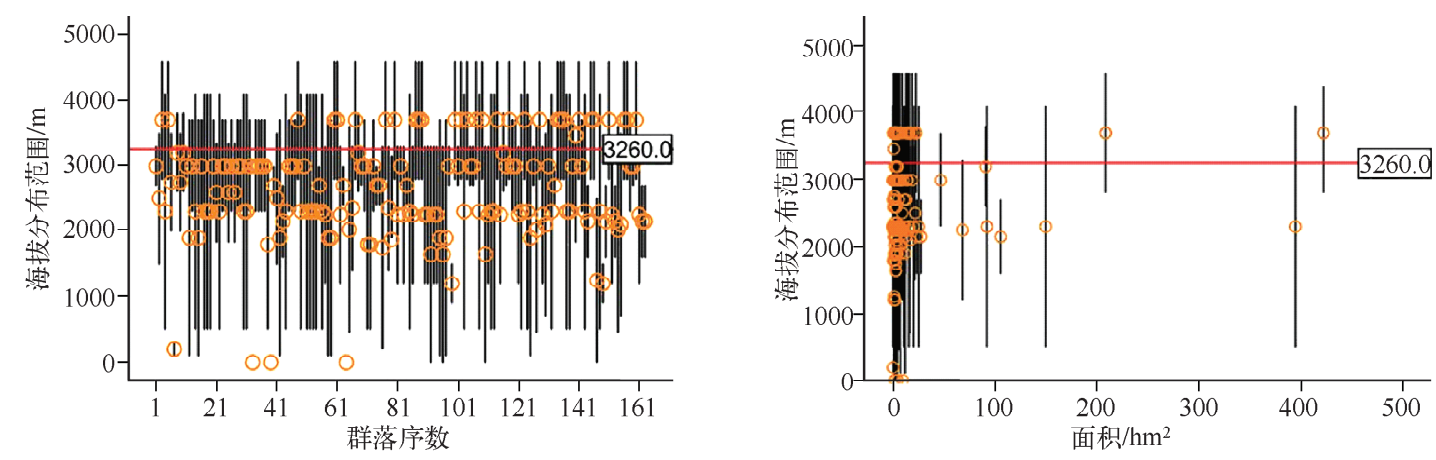

图 4 纳帕海各植物群落中优势种、群落面积及其海拔分布范围 (坚线为该群落优势物种的 $R_{\mathrm{s}}$ 上、下限范围; 小圆圈为 $R_{\mathrm{m}}$; 红色参考线为 $E_{\mathrm{r}}$ )

Fig. 4 Distribution situation of the $R_{\mathrm{s}}$ of each plant community and its corresponding area in Lake Napahai

\section{3 纳帕海优势植物的 $R_{\mathrm{s}} 、 M_{\mathrm{sh}}$ 与其分布面积的相关性}

除去农地、猪拱地和 $R_{\mathrm{s}}$ 信息缺失这 3 类斑块面积,并将同类群落斑块进行合并求和, 21 个优势物种的面 积与其 $R_{\mathrm{s}} 、 M_{\mathrm{sh}}$ 的关系散点图如 5 所示. 物种分布面积与其 $R_{\mathrm{s}}$ 经 Pearson (线性相关检验) 及 Spearman (非线性 相关检验) 双侧检验, 都无明显相关性, 说明物种 $R_{\mathrm{s}}$ 的宽度只能表明其生存的海拔范围的大小, 与该物种在 某一海拔现实生境中的分布优势度并无明显相关性. 而物种分布面积与 $M_{\mathrm{sh}}$ 的散点图经 Spearman 相关性双 侧检验, 相关系数为 -0.624 (在 0.01 水平上存在显著相关), 二者之间存在较显著的负相关, 此二变量散点 图的拟合曲线为 $y=-213 \ln x+1710\left(R^{2}=0.438\right)$ (图 5).

\section{4 结论与讨论}

\section{1 水因子对纳帕海植物分布格局的影响}

与同海拔的中生或旱生生境相比, 纳帕海较丰富的水因子并不是单纯随地理海拔变化的结果, 但对系 统内的各物种而言, 仍然满足本研究的假设, 即在主导因子相同的基础上, 各物种还同时承受随海拔而变化 的综合生态因子如光、热、降雨等的综合影响.

纳帕海地势平坦, 在丰水期的湖面与枯水期的草甸存在一系列中间阶段. 本研究中群落分布情况与孙 广友于 1981 年 5-9 月 ${ }^{[24]}$ 、肖德荣于 2005 年 8-10 月 ${ }^{[25]}$ 对纳帕海的研究资料相比较, 3 期数据都显示出水 

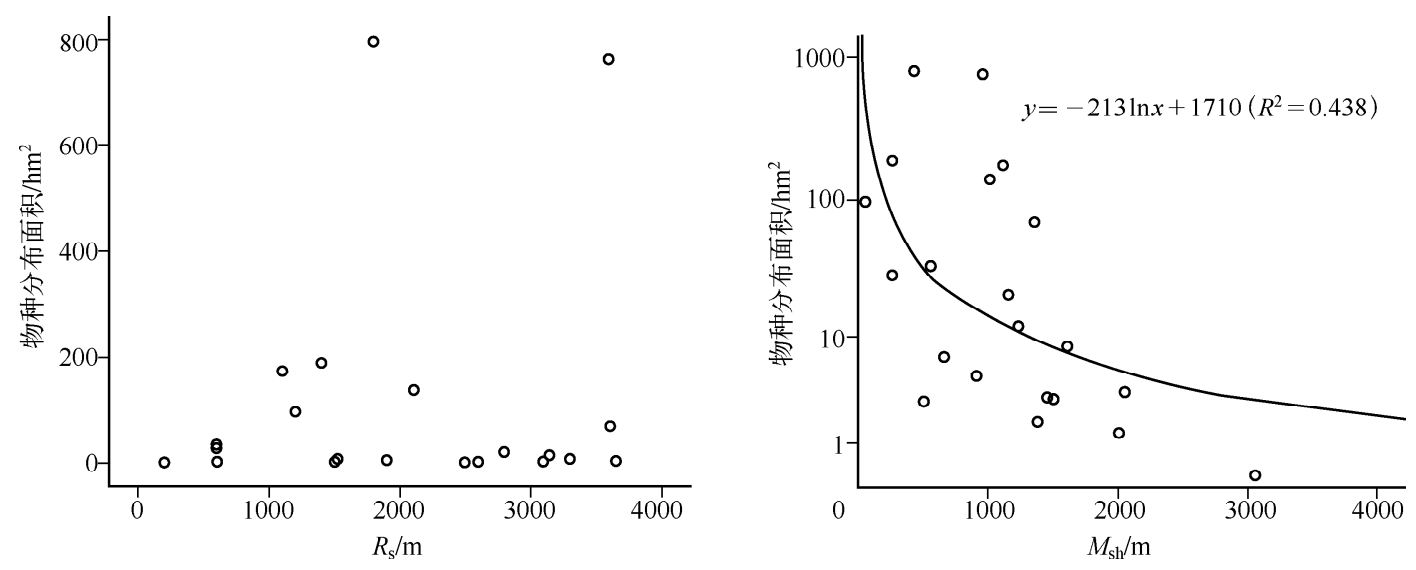

图 5 物种分布面积与其 $R_{\mathrm{s}}$ 和 $M_{\mathrm{sh}}$ 的关系 ( $y$ 轴经过对数变换)

Fig. 5 Correlation between dominant specie's distribution area and its corresponding $R_{\mathrm{s}}$ and $M_{\mathrm{sh}}$

生植物群落的位置和面积差异极大, 说明这种平坦地形条件下水因子分布梯度在人为干扰、牲畜踩踏的情 况下都会有很大的随机性.

如图 6a 所示, 2011 年 6 月纳帕海卫星影像中显示的水因子仅分布于北端的局部地段,仅考虑此表相, 容易得出除北部积水区域外其它地段都是中生或旱生生境的错误结论. 实际上在其它局部地段均有较丰富 的水量分布, 但由于植被覆盖不能显示出来. 本研究根据图 2 所示的水生植物群落, 求出它们的质心, 用各 水生群落面积进行赋值 (因纳帕海地势平坦, 各群落水因子分布差异主要体现在局部水域面积上), 进行 Spline 插值运算, 得到图 $6 \mathrm{~b}$ 所示水因子分布,显示水因子分布共 20 个等级, 颜色由深到浅依次表示水因子 丰富度的递减. 由水生植物群落反演得到的水因子分布梯度有两个明显的特点:一是在纳帕海平坦的地形 条件下,积水地段与非积水地段并不是截然分开的,而是渐变的,与实际情况相符合,与占总面积 $77 \%$ 的湿 生一中生物种水因子适应特征相符合; 二是该水因子梯度分布分析方法避免了仅以明水面判读卫星影像导 致严重缩小水因子分布面积这样的错误判断.

研究区域内优势物种多为水生、水生一湿生、湿生一中生、水生一湿生一中生这样的水因子主导类型, 这种 物种分布格局是在生境中水因子剧烈变化的影响下形成的,研究区域内少量的中生(旱生)物种在时间及空 间分布上都不能占据优势. 有观点认为, 研究生物多样性时应当考虑到生态系统生境与物种之间潜在的匹 配关系 ${ }^{[26]}$,这种匹配关系,使得当同一地段的土地类型随水因子变化而在沼泽、沼泽化草甸、草甸等不同类 型之间发生变化时,这些群落仍能在水因子改变的情况下保持一段时间的稳定性,并能以当前群落种子库 为基础进行下一阶段的演替.

\section{$4.2 R_{\mathrm{s}} 、 M_{\mathrm{sh}}$ 对纳帕海物种分布格局的影响}

研究区域内物种处在同一主导因子 (水因子) 和相同竞争等级 (草本) 的条件下,各物种的分布面积存 在很大的差距, 表明同样的生境对各物种的综合生态因子需求满足程度并不一样, 这将有赖于本研究的假 设与验证结果进行解释.

1) $R_{\mathrm{s}}$ 宽度与物种分布面积并无明显相关性,这表明 $R_{\mathrm{s}}$ 宽度是物种对综合环境耐受力的上、下限之间的 范围,与物种能否获得最佳生存发展条件并无直接关系,假设 1 未能获得证明.

2) 物种的 $M_{\mathrm{sh}}$ 与其分布面积存在明显的负相关关系, 即 $M_{\mathrm{sh}}$ 越小, 则说明物种所处的现实海拔越靠近 $R_{\mathrm{m}}$, 从而有更大的分布面积, 其内在原因可能是在这种情况下该物种能获得更佳程度的综合生态因子满足, 该结论可表述为: “在相同竞争等级中,在满足主导生态因子的情况下,某物种所处的现实海拔越接近其海 拔分布的中间值, 该物种较其它物种越能获得更佳的生存发展状态, 拥有越强的竞争力, 进而表现为有越大 的分布面积”,假设 2 得到了很好的验证.

研究区域内分布面积最多的物种, 均是 $M_{\mathrm{sh}}$ 较小且与水因子分布相适应的蒴麻、圆囊薹草 (Carex orbicul- 

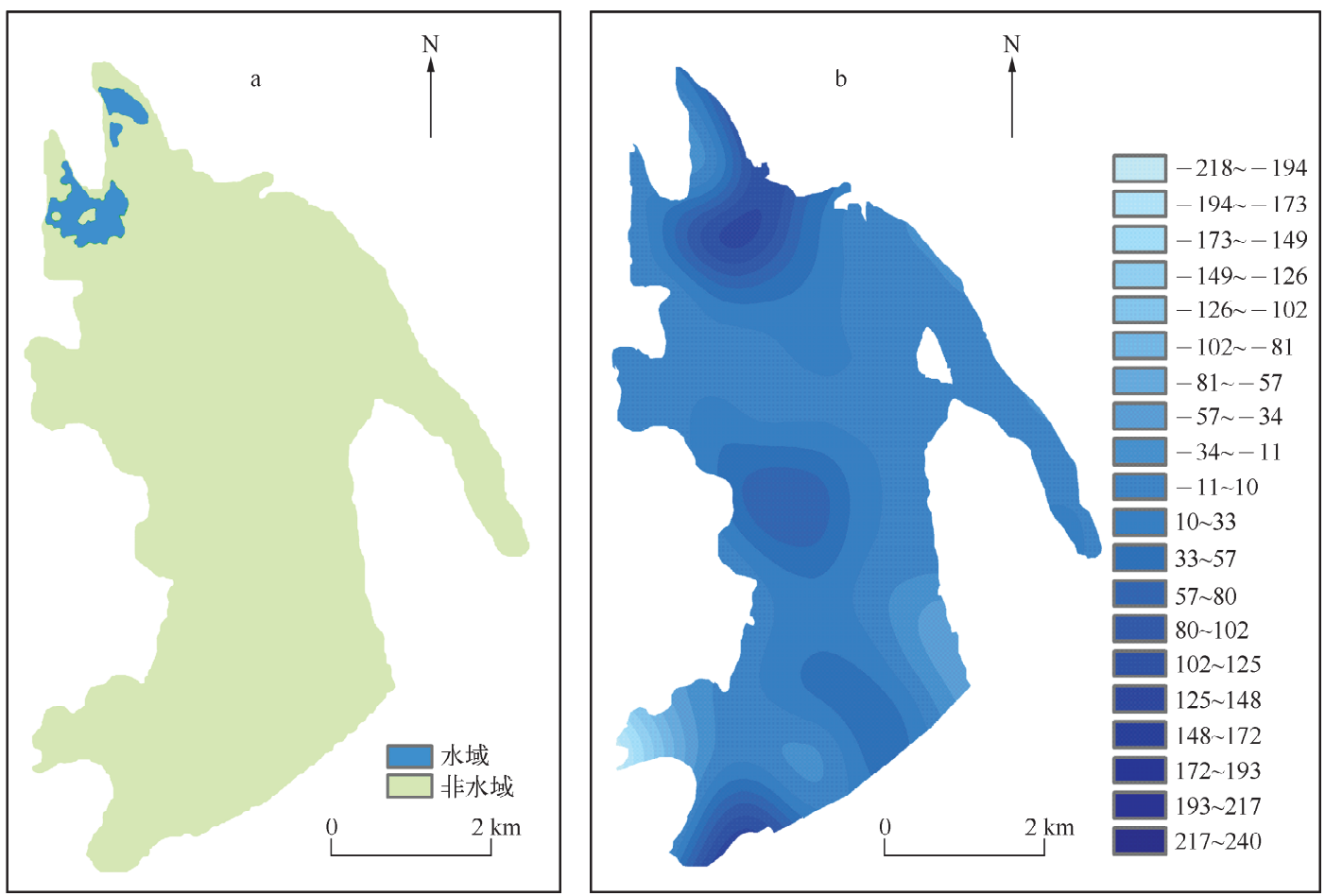

图 62011 年 6 月纳帕海水因子分布的两种测量结果 ( $\mathrm{a}$ : 以卫星影像明水面勾绘; $\mathrm{b}$ : 以水生植物群落进行插值计算)

Fig. 6 Different measuring results of water factor distribution in Lake Napahai in June, 2011

aris)、华扁穗草(Blysmus sinocompressus) 等湿生一中生物种, 它们的分布面积与其 $M_{\mathrm{sh}}$ 在各种强烈干扰下仍表 现出明显的对数负相关关系. 而杉叶藻 (Hippuris vulgaris)、小黑三棱 (Sparganium simplex)、刘氏芓荠(Heleocharis liouana) 等物种虽然有很小的 $M_{\mathrm{sh}}$, 但是由于纳帕海目前在时空维度总体上常常处于湿生一中生状态, 未能很好满足这些水生一湿生型物种的生态主导因子而使其分布面积的优势得不到充分体现,但在 $1960 \mathrm{~s}$ 、 1970s 开始季节性疏干湖水前, 这 3 个物种有较大分布面积, 说明如果其主导因子得到满足 (常年淹水), 它 们将成为优势物种, 从反面进一步验证了本研究的假设.

\section{$4.3 M_{\mathrm{sh}}$ 概念的潜在用途}

物种 $M_{\mathrm{sh}}$ 是一个由 $R_{\mathrm{s}}$ 与 $E_{\mathrm{r}}$ 所决定的动态参量, 它与物种分布面积的关系表征了物种对环境综合生态因 子的适应能力, 或可作为定量研究物种对环境适应能力的一个指示指标, 该指示指标可能对解释生态系统 内物种分布格局有重要的生态意义.

1) 与 $M_{\mathrm{sh}}$ 相似,生态位概念也强调 “物种的功能、适应和分布特征 ${ }^{[27]}$ ”, 在生态系统动态 ${ }^{[28]}$ 、群落结构和 多样性 ${ }^{[29]}$ 、外来植物人侵机制 ${ }^{[30-31]}$ 等方面也有普遍应用, 且均与群落分布格局相关, 但它的概念及其测度的 定义至今争议较大 ${ }^{[32]}$, 实际常见的测度方法 (如 Levins 指数、Shannon-Wiener 指数、Hurlbert 指数等) 都是以 物种按资源利用梯度在地理空间上的分布情况为基础. 这种相似性使得在研究物种分布格局、种间竞争、群 落演替等内容时, 可把 $M_{\mathrm{sh}}$ 作为生态位定量研究的一个替代指标, 此时, “越小” 的 $M_{\mathrm{sh}}$ 值, 等同于某物种在某 海拔上有“越宽”的生态位.

2) 有形的地理斑块 (包括廊道和基质) 是研究景观格局的基本要素 ${ }^{[33]}$, 通过技术分析其时空异质性, 实 现对生态过程的研究 ${ }^{[34]}$. 实际上生态景观不仅指有形的地理和生物景观, 还包括了无形的个体与整体、内部 与外部、过去和未来以及主观与客观间的系统耦合关系 ${ }^{[35]}$, 如目前除景观遗传学已将种群遗传学、景观生态 学和空间统计学进行了融合研究 ${ }^{[36]} . M_{\mathrm{sh}}$ 结合地理信息可作为无形景观进行可视化分析, 图 7 显示了以各群 
落质心分别以物种 $M_{\mathrm{sh}}$ 进行赋值 (对农地和猪拱地赋值为 0 ) 后进行反距离权重 IDW 插值运算得到的 $60 \sim 3260 \mathrm{~m}$ 区间 $M_{\mathrm{sh}}$ 的梯度分布, 这样的无形景观直观地反映了不同 $M_{\mathrm{sh}}$ 与其相应的面积分布情况, 其蕴含 的生态意义值得进一步深人研究.

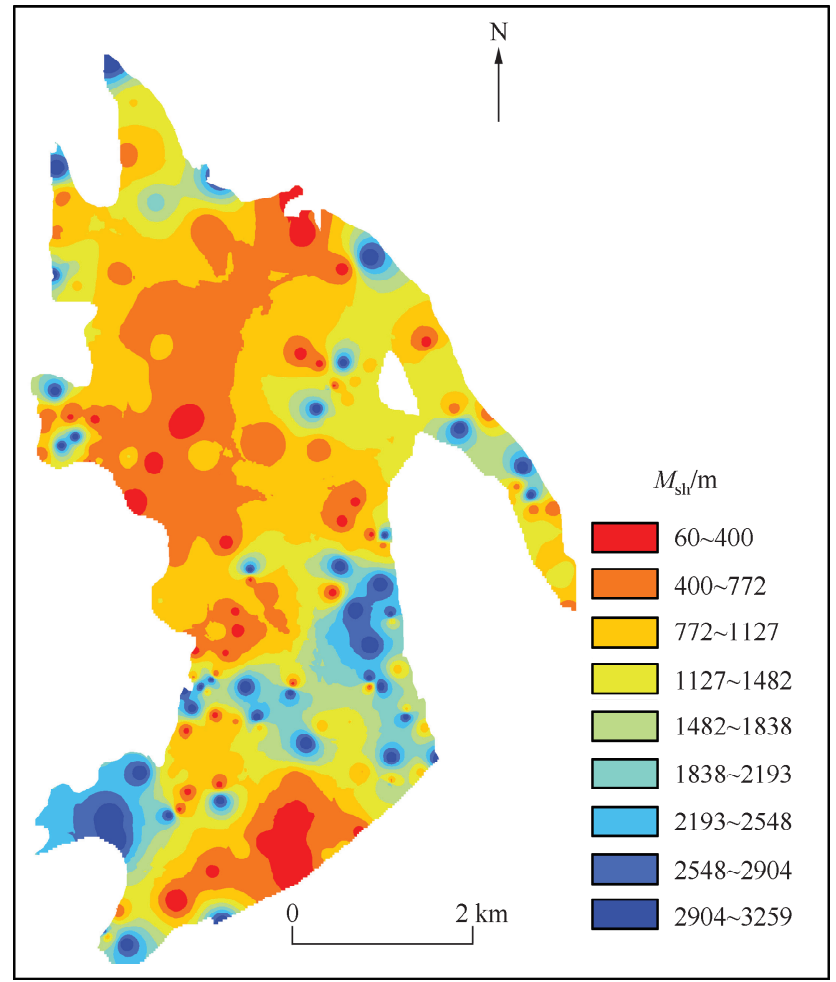

图 7 纳帕海 $M_{\mathrm{sh}}$ 分布梯度

Fig. $7 M_{\text {sh }}$ gradient distribution in Lake Napahai

致谢: 西南林业大学国家高原湿地研究中心喻庆国老师给予本研究野外调查和论文撰写以细致指导,特表 深切谢意!

\section{5 参考文献}

[ 1 ] Gaston KJ. The structure and dynamics of geographic ranges. Oxford: Oxford University Press, 2003.

[2] 梁 军, 沈泽吴. 关于种域的 Rapoport 法则检验、算法比较及中域效应消减一以云南无量山种子植物为例. 山地学 报,2010,28(5) :526-533.

[3] 冯建孟, 王襄平, 方精云. 云南独龙江地区种子植物物种多样性垂直分布格局和 Rapoport 法则的验证. 北京大学学 报: 自然科学版,2006,(4):515-520.

[ 4 ] Buckley J, Bridle JR, Pomiankowski A. Novel variation associated with species range expansion. BMC Evolutionary Biolo$g y, 2010,10: 382-384$.

[ 5 ] Silva LCR, Giorgis MA, Anand M et al. Evidence of shift in C4 species range in central Argentina during the late Holocene. Plant and Soil, 2011,349 :261-279.

[ 6 ] Markus P, Salinger M, Haun T et al. Factors and processes shaping the population structure and distribution of genetic variation across the species range of the freshwater snail radix balthica(Pulmonata, Basommatophora). BMC Evolutionary Biology, $2011,11: 135-148$.

[ 7 ] 王长庭, 王启基, 龙瑞军等. 高寒草甸群落植物多样性和初级生产力沿海拔梯度变化的研究. 植物生态学报, 2004, (2) :240-245. 
[8] 李凯辉, 胡玉昆, 王 金等. 不同海拔梯度高寒草地地上生物量与环境因子关系. 应用生态学报, 2007, (9): 2019-2024.

[ 9 ] 贾开心, 郑 征, 张一平. 西双版纳橡胶林生物量随海拔梯度的变化. 生态学杂志, 2006, (9):1028-1032.

[10］宋璐璐,㚞江文, 吴绍洪. 植物叶片性状沿海拔梯度变化研究进展. 地理科学进展,2011,(11):1431-1439.

[11] 徐鹏涁. 中国温带地区 4 种针叶林树种叶属性对海拔梯度的响应研究 [学位论文]. 兰州: 兰州大学,2012.

[12] 张育新, 马克明, 祁 建等. 北京东灵山海拔梯度上辽东栋种群结构和空间分布. 生态学报, 2009,29(6): 2789-2796.

[13] 高 远,慈海金金, 邱振鲁等. 山东蒙山植物多样性及其海拔梯度格局. 生态学报,2009,29(12):6377-6384.

[14] Colwell RK, Rahbek C, Gotelli NJ. The Mid-domain effect and species richness patterns: What have we learned so far. The American Naturalist, 2004,163 : E1-23.

[15］王襄平,方精云, 唐志尧. 中域效应假说: 模型、证据和局限性. 生物多样性,2009,(6) :568-578.

[16] 李 恒. 横断山区的湖泊植被. 云南植物研究, 1987,9(3):257-270.

[17] 田 昆, 常凤来, 陆 梅等. 人为活动对云南纳帕海湿地土壤碳氮变化的影响. 土壤学报, 2004,41 (5):681-686.

[18] 徐守国,郭辉军,田 昆等. 高原湿地纳帕海水生植被调查与分析. 山东林业科技,2006,4:48-50.

[19] 王利民, 寸玉康,陈奇伯. 滇西北高原水土保持生态修复措施的群落结构研究. 水土保持研究, 2006,13(3):85-87.

[20］李宁云. 纳帕海湿地生态系统退化评价指标体系研究 [学位论文]. 昆明:西南林业大学,2006.

[21] 李 恒. 云南湿地植物名录. 北京:科学出版社, 2009 .

[22] 刘劲松,陈 辉,杨涁云等. 河北省年均降水量插值方法比较. 生态学报,2009,29(7):3493-3500.

[23] 邓晓斌. 基于 ArcGIS 两种空间插值方法的比较. 地理空间信息,2008,(6):85-87.

[24] 孙广友. 横断山滇西北地区沼泽成因、分布及主要类型的初步探讨. 见: 黄锡畴编. 中国沼泽研究. 北京: 科学出版 社, $1988: 275-283$.

[25] 肖德荣. 滇西北典型高原湿地植物群落分布格局及驱动力 [学位论文]. 昆明: 西南林业大学, 2007.

[26] Partel M, Szava-Kovats R, Zobel M. Dark diversity: shedding light on absent species. Trends in Ecology and Evolution, 2011,26 (3): 124-128.

[27] 李景文. 森林生态学:第 2 版. 北京: 中国林业出版社,1994.

[28] 汤景明, 艾训儒, 易咏梅等. 鄂西南木林子常绿落叶阔叶混交林恢复过程中优势树种生态位动态. 生态学报, 2012, $32(20): 6334-6342$.

[29] Matthew DP, Stuart JD, William H et al. Habitat heterogeneity and niche structure of trees in two tropical rain forests. Oecologia, $2004,139: 446-453$.

[30] 王运生,谢丙炎,万方浩等. 应用生态位模型研究外来入侵物种生态位漂移. 生态学报,2008,28(10):4974-4981.

[31] 洪思思, 缪崇崇, 方本基等. 浙江省阔叶丰花草人侵群落物种多样性、生态位及种间联结研究. 武汉植物学研究, 2008, , (5) :501-508.

[32] 李 契,朱金兆,朱清科.生态位理论及其测度研究进展. 北京林业大学学报,2003,25(1):100-107.

[33] 汪永华. 景观生态学研究进展. 长江大学学报:自然版,2005,2(8) :79-83.

[34] 朱槐文,孟庆香, 宋二红等. 景观格局-生态过程研究进展. 湖北农业科学, 2010,49(1):211-214.

[35] Decker J. Wandering ecologies: The landscape architecture of Charles Anderson. Hiroshima: Design Media Publishing Ltd, 2013.

[36] 薛亚东,李 丽,吴巩胜等. 景观遗传学:概念与方法.生态学报,2011,31(6):1756-1762. 